\title{
Turgescência de crisântemos após a colheita utilizando o equipamento Wiltmeter ${ }^{\circledR}$
}

\author{
Postharvest turgidity of chrysanthemums using the equipment Wiltmeter ${ }^{\circledR}$
}

\author{
Poliana Cristina Spricigo ${ }^{\mathrm{I}}$ Marcos David Ferreira ${ }^{\mathrm{II}}$ Adonai Gimenez Calbo ${ }^{\mathrm{II}}$
}

RESUMO

O objetivo deste trabalho foi determinar a qualidade e mensurar a turgescência em hastes florais de crisântemos armazenadas em água potável e água destilada, utilizando o método de teor relativo de água (TRA) e o equipamento Wiltmeter ${ }^{\circledR}$ para determinação da pressão de turgescência. As hastes foram colhidas em um campo comercial de flores e acondicionadas ao acaso unitariamente em recipientes contendo água destilada ou água potável. Para acompanhar a condição hídrica das hastes, foram realizadas avaliações da variação da massa fresca, taxa de absorção de água, taxa de transpiração de água, teor relativo de água e pressão de turgescência. Os dados foram submetidos à análise de variância pelo teste $F$ e as médias comparadas ao longo dos dias de vida de vaso, utilizando-se o teste de Tukey a 5\% de significância. Para comparação do TRA e a pressão de turgescência, foi calculado o coeficiente de correlação de Pearson. As hastes mantidas em água potável obtiveram melhor resultado na manutenção da turgescência. Há correlação entre as avaliações de pressão de turgescência e o teor relativo de água, que se mantêm mais altas à medida que os tecidos vegetais estão novos e bem hidratados. A estimativa da pressão de turgescência foi eficiente e sensível na avaliação da condição hídrica dos tecidos das hastes de crisântemos cortados.

Palavras-chave: pressão de turgescência, teor relativo de água, Dendranthema morifolium.

\section{ABSTRACT}

The main goal of this research was to determine the quality by measuring turgor in flowers stems of chrysanthemums stored in tap water and on distilled water, using the method of relative water content (RWC) and the equipment Wiltmeter ${ }^{\circledR}$. The flower stems were harvested in a commercial field and placed randomly into unitary containers containing distilled water or tap water. In order to monitor the water status of the stems the follow analyses were done: variation of fresh mass, water absorption rate, water transpiration rate, relative water content and turgor pressure. Data were subjected to analysis of variance by $F$ test, means were compared through the days of vase life, using Tukey test at 5\% significance level. For comparison of the RWC and the turgor pressure the Pearson correlation coefficient was calculated. Flower stems kept in tap water maintained turgor significantly better than the ones maintained on distilled water. There is a correlation between turgor pressure and relative water content, which remain higher as the plant tissues are new and well hydrated. The estimate of the turgor pressure was effective and sensitive in evaluating the water status of the tissues of the stems of cut chrysanthemums.

Key words: turgor pressure, relative water content, Dendranthema morifolium.

\section{INTRODUÇÃO}

A floricultura brasileira movimenta anualmente no mercado interno um valor de US\$ 1,3 bilhão (ANUÁRIO, 2007). Segundo GRUSZYNSKI (2001), o crisântemo é uma das principais flores comercializadas no Brasil. Estudos feitos em São Paulo mostram que ele se encontra em primeiro lugar quanto à receita gerada por flores comercializadas, apesar de estar em segundo lugar quanto ao volume (IBRAFLOR, 2004).

IUniversidade Estadual de Campinas (UNICAMP), Campinas, SP, Brasil.

IIFaculdade de Engenharia Agrícola, UNICAMP, 13083-875, Campinas, SP, Brasil. E-mail: marcosferreira@cnpdia.embrapa.br. Autor para correspondência.

IIIEmbrapa Instrumentação, São Carlos, SP, Brasil. 
A durabilidade das flores após o corte é resultado de alterações fisiológicas e depende da quantidade de reservas que as hastes florais apresentam, assim como da ocorrência de bactérias e fungos, injúrias físicas aos tecidos, e perda excessiva de água (HARDENBURG et al., 1986; BRACKMANN et al., 2004). O balanço hídrico envolve processos fisiológicos de absorção, transporte e perda de água com a capacidade dos tecidos de retê-la, e todos esses processos se inter-relacionam (DIAS-TAGLIACOZZO et al., 2005). A qualidade da água na qual as flores são armazenadas é um fator que influencia na longevidade das hastes. A água é o meio para difusão de solutos e funciona como regulador da temperatura, além de ser fundamental na sustentação dos tecidos vegetais, à incompressibilidade e ser o solvente para a maioria das reações bioquímicas (REICHARDT, 1985).

A turgescência em hastes florais pode ser estimada utilizando-se de inúmeros métodos diferentes. No teor relativo de água, segundo o método de CATSKY (1974), a relação entre massa fresca, túrgida e seca representa o conteúdo de água no momento da amostragem. Contudo, os resultados deste método não são obtidos no ato da amostragem e são destrutivos. No momento da obtenção efetiva da porcentagem de água no produto, ele apresentará outras características, eliminando então a possibilidade de avaliação da qualidade durante o transporte e comercialização.

Medições que sejam objetivas são fundamentais, pois a obtenção de dados reais possibilita que haja uma ação localizada sobre o fator depreciativo do produto. OWiltmeter ${ }^{\circledR}$ é um tipo de aplanador para medir a firmeza dependente da turgescência celular de folhas e de segmentos planares de órgãos (CALBO et al., 2010).

Para aplicar a técnica de aplanação, o Wiltmeter ${ }^{\circledR}$ faz uso de um anteparo contendo um elemento poroso por onde escoa um fluxo de ar. No método rápido, descrito por CALBO et al. (2010), na placa de aplanação especial, um fluxo de ar gerado por um gradiente de pressão de $\approx 6 \mathrm{kPa}$ é escoado. Para a mensuração, o tecido vegetal é submetido à compressão em anteparo até que sua aplanação obstrua minimamente a passagem de ar através dos poros. A menor pressão que reduz o fluxo de ar até zero é a estimativa da pressão de aplanação e do turgor celular. O equipamento possui um manômetro, em que é realizada a leitura da pressão de turgescência, que é simples, portátil e de fácil uso. É adequado para avaliação objetiva e rápida da qualidade de folhosas. O objetivo deste trabalho foi determinar a qualidade e mensurar a turgescência em flores e folhas de crisântemos pelos métodos de teor relativo de água e da pressão de turgescência em hastes armazenadas em água potável e água destilada.

\section{MATERIAL E MÉTODOS}

Hastes de Dendranthema morifolium cv. 'Calabria' foram colhidas em campo de cultivo da empresa Terra Viva, em Holambra, SP, e transportadas até o laboratório na Faculdade de Engenharia Agrícola - UNICAMP. O transporte foi realizado com as hastes separadas em dois lotes, um em água destilada e outro em água potável. Foi realizada a seleção e a padronização das hastes e estas foram colocadas de forma unitária em recipientes cobertos com filme de PVC para minimizar a perda de água por evaporação.

A água foi trocada a cada dia de avaliação para minimizar o desenvolvimento de microrganismos. Os experimentos foram conduzidos com temperatura em $\pm 22^{\circ} \mathrm{C}$ e umidade relativa $75-85 \%$. A avaliação foi realizada em 0, 3, 6, 9 e 12 dias após a sua instalação, exceto as taxas de absorção e de transpiração que foram avaliadas diariamente.

Variação da massa fresca: as hastes inteiras foram pesadas em balança analítica com precisão de 0,01g e o resultado foi expresso em gramas.

Taxa de absorção e transpiração: determinadas conforme método descrito por VAN DOORN \& VASLIER (2002) e utilizada por VIEIRA (2008). A taxa de absorção de água foi obtida pelo volume consumido, em $\mathrm{mg} \mathrm{g}^{-1} \mathrm{MF} \mathrm{dia}^{-1}$, sendo calculada pela fórmula: $\mathrm{V}=(\mathrm{PSi}-\mathrm{PS}) / \mathrm{PHi}$, em que $\mathrm{V}$ : volume de solução absorvida ( $\mathrm{mg} \mathrm{g}^{-1} \mathrm{MF} \mathrm{dia}^{-1}$ ); PSi: massa inicial da solução (mg); PSf: massa final da solução (mg); PHi: massa final da haste (mg). A taxa de transpiração foi estimada, em $\mathrm{mg} \mathrm{g}^{-1} \mathrm{MF}$ dia $^{-1}$, em que: $\mathrm{T}=\mathrm{V}$ - (PH (f)PH (i)); em que T: taxa de transpiração; V: volume de solução absorvida; PH (i): massa da haste no início; PH (f): massa da haste no final.

Teor relativo de água: conforme método descrito por CATSKY (1974). As folhas das hastes foram amostradas de forma unitária a cada dia de avaliação e as lígulas agrupadas em dez. Foram pesadas para obtenção da massa fresca, e submersas em água. As folhas e lígulas permaneceram sob água por 24 horas, quando foi realizada uma nova pesagem para obtenção da massa túrgida. Em seguida, foram colocadas em estufa a $70^{\circ} \mathrm{C}$ por 72 horas para obtenção da massa seca. O TRA foi calculado com a equação proposta por WEATHERLEY (1950): TRA = 100 (MF MS) / (MT - MS); em que: TRA: teor relativo de água, expresso em \%; MF: massa fresca (g.); MS: massa seca (g.), e MT: massa túrgida (g.).

Pressão de turgescência: foi utilizado o Wiltmeter ${ }^{\circledR}$, com leituras feitas pelo método rápido, descrito por CALBO et al. (2010). Para a mensuração, o tecido avaliado foi pressionado por uma membrana 
flexível contra uma placa de aplanação até que o amassamento se igualasse à pressão de turgescência celular e obstruísse a passagem de ar, condição em que se leu a pressão no manômetro, sendo três lígulas e uma folha por haste.

Correlação entre os dados de teor relativo de água e pressão de turgescência: calculado utilizando a Correlação de Pearson (r), índice sem dimensão situado entre -1,0 e 1,0 inclusive 0 , reflete a extensão de uma relação linear entre conjuntos de dados, pela fórmula: $r=\left(\sum(x-\bar{x})(y-\bar{y})\right) /\left(\sqrt{\sum(x-\bar{x})^{2} \sum(y-\bar{y})^{2}}\right)$

Nela, $x$ e $y$ representam as médias aritméticas de cada uma das as variáveis (teor relativo de água e a pressão de turgescência). Valores próximos a: $0=$ correlação fraca; 1 = correlação perfeita positiva; -1 = correlação perfeita negativa.

Os dados foram submetidos à análise de variância, pelo teste $\mathrm{F}$, com médias comparadas ao longo dos dias, utilizando-se o teste de Tukey a 5\% de significância.

\section{RESULTADOS E DISCUSSÃO}

A massa fresca das hastes, acondicionadas em água destilada e água potável, diferiu significativamente entre si e ao longo dos dias de armazenamento (Tabela 1). Para ambos os tratamentos, houve elevação na massa fresca (\%) até o dia 9, contudo, a água potável foi responsável por manter níveis de hidratação mais elevados. Este comportamento pode ser atribuído à presença de íons

Tabela 1 - Variação da massa fresca acumulada (\%) em hastes de crisântemos submetidas a diferentes tratamentos póscolheita, mantidas a $\pm 22^{\circ} \mathrm{C}$ e $85 \%$ de umidade relativa.

\begin{tabular}{ll}
\hline Tratamentos (T) & Variação da Massa fresca (\%) \\
\hline Água destilada & $106,5 \mathrm{~b}$ \\
Água potável & $107,6 \mathrm{a}$ \\
DMS & 1,1 \\
Dias de armazenamento (D) & \\
0 & $100,0 \mathrm{~b}$ \\
3 & $114,0 \mathrm{a}$ \\
6 & $113,5 \mathrm{a}$ \\
9 & $111,5 \mathrm{a}$ \\
12 & $96,1 \mathrm{~b}$ \\
DMS & 5,7 \\
Interação TxD & $n s$ \\
CV\% & 4,6 \\
\hline
\end{tabular}

*Para cada fator, médias seguidas de uma letra comum não diferem significativamente entre si, pelo teste de Tukey $(\mathrm{P} \quad 0,05)$ ${ }^{\text {n.s }}$ não significativo; ** significativo $(\mathrm{P}=0,05)$. DMS: diferença mínima significativa; C.V.: coeficiente de variação na água potável, que podem influenciar na mobilidade da água absorvida nos vasos condutores, além de prevenir o aparecimento de microrganismos pela ação no cloro. Segundo HARDENBURG et al. (1990), a água que apresenta $\mathrm{pH}$ alcalino diminui a mobilidade nos vasos condutores de flores em comparação à utilização de soluções ácidas. VAN MEETEREN et al. (2000) mostraram que a água potável influenciou positivamente no balanço hídrico de hastes de crisântemos, em virtude da existência de vários íons em baixa concentração na solução.

A utilização da água potável, inclusive como tratamento controle, reproduz com proximidade o manejo usado entre produtores e consumidores, contudo há grande variabilidade na água potável dependente da sua região de origem.

A quantidade de água absorvida pelas hastes foi significativamente maior quando acondicionadas em água potável (Tabela 2). De forma semelhante, VAN MEETEREN et al. (2000) testaram a qualidade pós-colheita de crisântemos acondicionados em água potável e água desionizada, constatando que em 3 dias flores mantidas em água desionizada apresentaram forte declínio da massa fresca, aumentando em 50 vezes a resistência hidráulica na parte basal. A taxa de absorção de água de flores cortadas depende da sua condutância hidráulica e da diferença de potencial hídrico entre a solução e os tecidos das hastes. O potencial hídrico é afetado pela perda de água devido à transpiração e, também, por outros processos celulares especialmente crescimento das pétalas durante o florescimento (VAN MEETEREN \& VAN GELDER, 1999).

Diferenças significativas foram observadas entre os tratamentos e ao longo dos dias de armazenamento, com maior absorção até o $3^{\circ}$ dia e tendência de diminuição nos dias seguintes (Tabela 3). Resultado obtido por ANTES et al. (2009) demonstrou que água potável e água esterilizada não foram eficazes durante a reabsorção de água na pós-colheita, mas, utilizando conservantes florais, a absorção de água manteve-se maior durante os três primeiros dias naqueles tratamentos. Já para flores cortadas de bocade-leão (Antirrhinum majus L.), a taxa de absorção de diferentes soluções foi maior nas primeiras 24 horas, seguido de decréscimo ao longo do tempo de avaliação (VIEIRA, 2008).

Nas hastes colocadas em água destilada e água potável, houve interação entre os tratamentos para a taxa de transpiração (Tabela 2). Ao longo do armazenamento, parte da água contida na haste e a absorvida perdeu-se gradativamente para a atmosfera (Tabela 3). 
Tabela 2 - Taxa de absorção e transpiração $\left(\mathrm{mg} \mathrm{g}^{-1} \mathrm{MF}^{-1}\right.$ dia $\left.^{-1}\right)$ em hastes de crisântemos submetidas a diferentes tratamentos pós-colheita, mantidas a $\pm 22^{\circ} \mathrm{C}$ e $85 \%$ de umidade relativa.

\begin{tabular}{|c|c|c|c|c|}
\hline Fontes de variação & GL & SQ & QM & $\mathrm{F}$ \\
\hline Tratamentos (F1) & 1 & 0,0321 & 0,0321 & $5,4281^{*}$ \\
\hline Dias de armazenamento (F2) & 11 & 0,0618 & 0,0556 & $9,4926 * *$ \\
\hline Interação F1xF2 & 11 & 0,1541 & 0,0140 & $2,3693^{*}$ \\
\hline Tratamentos & 23 & 0,8037 & 0,0349 & $5,9091^{* *}$ \\
\hline Resíduo & 120 & 0,7097 & 0,0059 & \\
\hline Total & 143 & 1,5134 & & \\
\hline Fontes de variação & GL & SQ & QM & F \\
\hline Tratamentos (F1) & 1 & 0,0860 & 0,0860 & $0,0936 n s$ \\
\hline Dias de armazenamento (F2) & 11 & 1426,4117 & 129,6738 & $141,0696^{* *}$ \\
\hline Interação F1xF2 & 11 & 34,9485 & 3,1771 & $3,4563 * *$ \\
\hline Tratamentos & 23 & 1461,4463 & 63,5411 & $69,1252^{* *}$ \\
\hline Resíduo & 120 & 110,3062 & 0,9192 & \\
\hline Total & 143 & 1571,7525 & & \\
\hline
\end{tabular}

** significativo em nível de $1 \%$ de probabilidade $(\mathrm{P}<0,01)$; * significativo em nível de $5 \%$ de probabilidade $(0,01 \leq \mathrm{P}<0,05)$; ns não significativo $(\mathrm{P} \geq 0,05)$

As hastes dos dois tratamentos não apresentaram diferenças significativas no teor relativo de água, tanto para lígulas quanto para folhas (Tabela 4), apresentando apenas variações em decorrência do tempo de armazenamento.

Observou-se que, ao longo dos dias, as folhas apresentavam ganho na porcentagem de água na avaliação com o TRA, contudo, este aumento da porcentagem de água nas folhas não foi constatado visualmente. Tecidos que estão sob estresse, mesmo sem sintomas aparentes, perdem massa fresca e, na fase para obtenção de massa túrgida, também podem absorver pouca água.

A pressão de turgescência apresentou resultados significativamente diferentes entre água destilada e potável, e modificações ao longo dos dias

Tabela 3 - Taxa de absorção de água e taxa de transpiração (mg g MF $^{-1}$ dia $^{-1}$ ) em hastes de crisântemos submetidas ao acondicionamento em água destilada e em água potável, mantidas a $\pm 22^{\circ} \mathrm{C}$ e $85 \%$ de umidade relativa.

\begin{tabular}{|c|c|c|c|c|c|c|}
\hline \multirow[t]{3}{*}{ Tratamentos } & \multicolumn{6}{|c|}{ 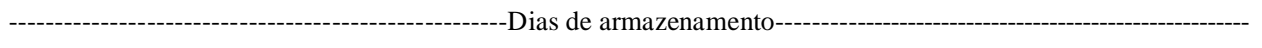 } \\
\hline & \multicolumn{6}{|c|}{ - } \\
\hline & 1 & 2 & 3 & 4 & 5 & 6 \\
\hline Água destilada & $0,23 \mathrm{aA}$ & $0,22 \mathrm{aAB}$ & $0,24 \mathrm{aA}$ & $0,16 \mathrm{bCD}$ & $0,18 \mathrm{bC}$ & $0,11 \mathrm{bEF}$ \\
\hline \multirow[t]{2}{*}{ Água potável } & $0,24 \mathrm{aA}$ & $0,25 \mathrm{aAB}$ & $0,25 \mathrm{aA}$ & $0,22 \mathrm{aAB}$ & $0,20 \mathrm{aB}$ & $0,12 \mathrm{aBC}$ \\
\hline & 7 & 8 & 9 & 10 & 11 & 12 \\
\hline Água destilada & $0,08 \mathrm{aB}$ & $0,12 \mathrm{aAB}$ & $0,13 \mathrm{aAB}$ & $0,13 \mathrm{aAB}$ & $0,18 \mathrm{aAB}$ & $0,06 \mathrm{aB}$ \\
\hline Água potável & $0,12 \mathrm{aBC}$ & $0,14 \mathrm{aBC}$ & $0,14 \mathrm{aBC}$ & $0,12 \mathrm{aBC}$ & $0,17 \mathrm{aBC}$ & $0,07 \mathrm{aC}$ \\
\hline \multirow{2}{*}{ Tratamentos } & \multicolumn{6}{|c|}{-------Taxa de transpiração---- } \\
\hline & 1 & 2 & 3 & 4 & 5 & 6 \\
\hline Água destilada & $3,82 \mathrm{aG}$ & $6,27 \mathrm{aF}$ & $9,41 \mathrm{aE}$ & $9,54 \mathrm{aE}$ & $9,49 \mathrm{aE}$ & $10,14 \mathrm{aDE}$ \\
\hline \multirow[t]{2}{*}{ Água potável } & $3,28 \mathrm{aF}$ & $4,53 \mathrm{bF}$ & $8,18 \mathrm{bE}$ & 9,33 aDE & $8,81 \mathrm{aDE}$ & $10,15 \mathrm{aD}$ \\
\hline & 7 & 8 & 9 & 10 & 11 & 12 \\
\hline Água destilada & 9,99 aDE & 10,49 bCDE & $12,19 \mathrm{aBC}$ & $12,95 \mathrm{aB}$ & $14,89 \mathrm{bA}$ & 11,69 aBCD \\
\hline Água potável & $10,37 \mathrm{aCD}$ & $12,25 \mathrm{aB}$ & $12,52 \mathrm{aB}$ & $13,55 \mathrm{aB}$ & 16,47 aA & 12,03 aBC \\
\hline
\end{tabular}

* Médias seguidas de pelo menos uma letra comum, maiúscula na linha e minúscula na coluna, não diferem significativamente entre si, pelo teste de Tukey $(\mathrm{P} \geq 0,05)$. 
Tabela 4 - Teor relativo de água (\%) e pressão de turgescência (kPa) em lígulas e folhas de crisântemos acondicionados em água destilada e água potável, mantidas a $\pm 22^{\circ} \mathrm{C}$ e $85 \%$ de umidade relativa.

\begin{tabular}{|c|c|c|c|c|}
\hline \multirow{2}{*}{ Tratamentos (T) } & \multicolumn{2}{|c|}{-------Teor relativo de água (\%)------- } & \multicolumn{2}{|c|}{-----Pressão de turgescência (kPa)------ } \\
\hline & Lígulas & Folhas & Lígulas & Folhas \\
\hline Água destilada & $91,11 \mathrm{a}$ & 88,35 a & $90,88 \mathrm{~b}$ & $98,27 \mathrm{~b}$ \\
\hline Água potável & 92,13 a & 91,81 a & 98,40 a & $105,02 \mathrm{a}$ \\
\hline DMS & 3,65 & 4,94 & 5,52 & 4,00 \\
\hline \multicolumn{5}{|c|}{ Dias de armazenamento (D) } \\
\hline 0 & $87,83 \mathrm{bc}$ & $83,20 \mathrm{~b}$ & $91,53 \mathrm{ab}$ & $96,85 \mathrm{~b}$ \\
\hline 3 & 85,63 с & $89,80 \mathrm{ab}$ & 88,67 b & $102,97 \mathrm{ab}$ \\
\hline 6 & $94,29 \mathrm{ab}$ & $92,67 \mathrm{a}$ & $99,30 \mathrm{ab}$ & $106,24 \mathrm{a}$ \\
\hline 9 & 96,24 a & 94,65 a & $101,33 \mathrm{a}$ & $100,52 \mathrm{ab}$ \\
\hline 12 & $94,11 \mathrm{ab}$ & - & $92,35 \mathrm{ab}$ & - \\
\hline DMS & 8,12 & 9,26 & 12,30 & 7,50 \\
\hline Interação TxD & ns & ns & ns & ns \\
\hline CV\% & 7,67 & 9,4 & 11,3 & 6,74 \\
\hline
\end{tabular}

*Para cada fator, médias seguidas de uma letra comum não diferem significativamente entre si, pelo teste de Tukey (P>0,05); ${ }^{\text {n.s. }}$, não significativo. DMS: diferença mínima significativa; CV: coeficiente de variação.

de armazenamento (Tabela 4). Pela pressão de turgescência, foi verificada que a água potável manteve os tecidos em melhor estado. Esse resultado corrobora a variação da massa fresca (Tabela 1), já que a água potável obteve melhor desempenho; com a taxa de absorção (Tabela 3), apresentando maior absorção de água e com a taxa de transpiração (Tabela 3), em que ambos os tratamentos não apresentaram diferenças. Isso significa dizer que, em água potável, as hastes absorveram mais água e transpiraram como as hastes em água destilada.

O coeficiente de correlação de Pearson para comparação de resultados entre TRA e pressão de turgescência tende a ser forte, perfeito e positivo, o que quer dizer que se um aumenta ou diminui o outro responde do mesmo modo. Em tratamentos e tecidos em que a perda de turgescência foi maior, o coeficiente de correlação tendeu a cair, pois os resultados do teor relativo de água e pressão de turgescência não mantiveram o mesmo comportamento.

Nas lígulas, os coeficientes de correlação de Pearson para TRA e pressão de turgescência para hastes de crisântemos acondicionados em água destilada e água potável foram de 0,63 e 0,99, respectivamente. Para folhas, os coeficientes são de 0,41 para água destilada e 0,75 para água potável. O coeficiente de correlação mais baixo para os tratamentos que apresentaram maior perda na turgescência sinaliza que a avaliação realizada pelo Wiltmeter ${ }^{\circledR}$ foi diferente daquela obtida pelo TRA, podendo esta avaliação estar mais próxima ao comportamento real dos tecidos das lígulas e folhas.

\section{CONCLUSÃO}

A água potável manteve as hastes mais túrgidas e foi eficiente na manutenção da qualidade dos crisântemos quando comparada ao tratamento com água destilada. Em comparação com o método do teor relativo de água, a utilização do equipamento Wiltmeter ${ }^{\circledR}$ com a estimativa do conteúdo de água por meio da pressão de turgescência foi mais sensível às alterações na turgescência, principalmente quando os tecidos estavam murchos.

\section{REFERÊNCIAS}

ANUÁRIO BRASILEIRO DAS FLORES. Santa Cruz do Sul, RS: Gazeta Santa Cruz, 2007. 112p.

ANTES, R.B. et al. Bloqueio vascular de hastes de gérberas cv. Patrizia. Biotemas, v.22, n.2, p.1-7, 2009. Disponível em: <http://www.biotemas.ufsc.br/volumes/pdf/volume222/ 1a7.pdf>. Acesso em: 12 dez. 2010.

BRACKMANN, A. et al. Qualidade de pré-colheita e vida de vaso de inflorescências de crisântemo 'Bronze Repin' com aplicação de aminoetoxivinilglicina. Revista da Faculdade de Zootecnia, Veterinária e Agronomia, v.11, p.107-115, 2004. Disponível em: <http://revistaseletronicas.pucrs.br/ojs/ index.php/fzva/article/view/2192>. Acesso em: 25 abr. 2009.

CALBO, A.G. et al. A leaf lamina compression method for estimating turgor pressure. Hortscience, 45, n.3, p.418-423, 2010. Disponível em: <http://hortsci.ashspublications.org/cgi/ reprint/45/3/418>. Acesso em: 12 dez. 2010.

CATSKY, J. Water saturation deficit (relative water content). In: SLAVIK, B. (Ed). Methods of studying plant water relations. 1974 . p.136-154.

Ciência Rural, v.42, n.2, fev, 2012. 
DIAS-TAGLIACOZZO, G.M. et al. Fisiologia pós-colheita de flores de corte. Revista Brasileira de Horticultura Ornamental, v.11, n.2, p.89-99, 2005. Disponível em: <http:/ /www.sbfpo.com.br/rbho/index.php/rbho/article/view/48/62>. Acesso em: 04 maio, 2010.

GRUSZYNSKI, C. Produção comercial de crisântemos: vaso corte e jardim. Guaíba: Agropecuária, 2001. 166p.

HARDENBURG, R.E. et al. The commercial storage of fruits, vegetables and florist and nursery stocks. Washington: U.S. Department of Agriculture, 1986. 136p.

HARDENBURG, R.E. et al. The comercial storage of fruits, vegetables and florists and nursey stocks. USDA, Agricultural Research Service. Washington: Agricultural Handbook, 1990. 130p.

INSTITUTO BRASILEIRO DE FLORICULTURA (IBRAFLOR). Desenvolvimento recente da floricultura no Brasil. Campinas, 2004. 25p.

REICHARDT, K. Processos de transferência no sistema solo-planta-atmosfera. Campinas: Fundação Cargill, 1985. 486p.

VAN DOORN, W.G.; VASLIER, N. Wounding-induced xylem occlusion in stems of cut chrysanthemum flowers: roles of peroxidase and cathechol oxidase. Postharvest Biology and
Technology, v.26, p.275-284, 2002. Disponível em <http:// www.sciencedirect.com/science/article/B6TBJ-460WH63-3/2/ 352c37d42bc8a4f306f168854b60065f>. Acesso em: 23 jun. 2010 .

VAN MEETEREN, U. et al. Reconsideration of the use of deionized water as vase water in postharvest experiments on cut flowers. Postharvest Biology and Technology, v.18, p.169-181, 2000. Disponível em: <http://www.sciencedirect.com/science/article/ B6TBJ-3XSJFK5-4/2/c30d40c7113f0b555929277ffbcdc378>. Acesso em: 19 maio, 2010.

VAN MEETEREN, U.; VAN GELDER H. Effect of time since harvest and handling conditions on rehydration ability of cut chrysanthemum flowers. Postharvest Biology and Technology, v.16, 169-177, 1999. Disponível em: <http:// www.sciencedirect.com/science/article/B6TBJ-3WP2P8M-8/ 2/0bef23d7b6a9783c1b643b5e68ff1ca0>. Acesso em: 25 jun. 2010 .

VIEIRA, L.M. Conservação pós-colheita de inflorescências de boca de-leão (Antirrhinum majus L.) em relação à condição hídrica das hastes. 2008. 53f. Dissertação (Mestrado em Fisiologia Vegetal) - Universidade Federal de Viçosa, MG.

WEATHERLEY, P.E. Studies in water relations of cotton plant. In: The field measurament of water deficits in leaves. New Phytology, v.49, p.81-97, 1950. Disponível em: <http:/ /www.jstor.org/pss/2428690>. Acesso em: 02 fev. 2010. 